\title{
Verifying the Effects of an Education Program Leveraging Information Technology to Promote Cervical Cancer Screening in Women Aged 20 - 29-A One-Year Longitudinal Study
}

\author{
Nakamura Tomoko1,2, Sasaki Ayako3 \\ ${ }^{1}$ Department of Nursing Science, Osaka Medical College, Takatsuki, Japan \\ ${ }^{2}$ Faculty of Nursing, Hyogo University, Kakogawa, Japan \\ ${ }^{3}$ Faculty of Nursing, Osaka Medical College, Takatsuki, Japan \\ Email: ntomoko@hyogo-dai.ac.jp
}

How to cite this paper: Tomoko, N. and Ayako, S. (2020) Verifying the Effects of an Education Program Leveraging Information Technology to Promote Cervical Cancer Screening in Women Aged 20 - 29-A One-Year Longitudinal Study. Health, 12, 1526-1542.

https://doi.org/10.4236/health.2020.1211111

Received: October 11, 2020

Accepted: November 27, 2020

Published: November 30, 2020

Copyright (c) 2020 by author(s) and Scientific Research Publishing Inc. This work is licensed under the Creative Commons Attribution International License (CC BY 4.0).

http://creativecommons.org/licenses/by/4.0/

(c) (i) Open Access

\begin{abstract}
The purpose of this research is to implement an IT-based education program in order to promote cervical cancer screenings for women aged 20 - 29 years, as well as to examine the results of said program. This is a longitudinal/comparative study of two groups, one for which the program was implemented (the intervention group), and the other for which it was not (the control group). The program consisted of attending a health lecture and encouragement to be screened one month, six months, and one year later sent through IT-based methods. The target was unmarried women aged 20 - 29 who had neither previously given birth nor had been screened for cervical cancer in a period one year prior. They were divided into two groups, the intervention group $(n=142)$ and control group $(n=145)$. The effectiveness of the program was assessed via an initial survey and further surveys six months and one year later. Results were based on the Japanese version of the Health Belief Model Scale for Cervical Cancer and the Pap Smear Test (HBMSCCPST), knowledge scores in the categories of Healthy Lifestyles, Cervical Cancer, Cervical Cancer Screening, and screening behavior. A two-way ANOVA of the HBMSCCPST subscales and knowledge scores in the initial, six-month, and one-year surveys was performed, showing interaction in Cervical Cancer $(\mathrm{p}=$ 0.00). Main effects were observed in Cervical Cancer Screening $(\mathrm{p}=0.00)$ and Healthy Lifestyles $(p=0.00)$. Regarding the amount of change from the initial survey, knowledge scores in the Cervical Cancer $(p=0.027)$ and Cervical Cancer Screening $(\mathrm{p}=0.016)$ categories were significantly higher in the intervention group than in the control group. There was no significant difference in
\end{abstract}


cervical cancer screening rates $(\mathrm{p}=0.26)$ between the two groups. However, a small-degree effect size was observed for Benefits, Seriousness, and Susceptibility subscales in both examinees and non-examinees. Although the educational program of this study was effective in improving the knowledge of women in their twenties, there was little improvement in HBMSCCPST and it did not lead to the promotion of cervical cancer screening. In order to raise interest in cervical cancer screening, it is necessary to consider useful content to guide women to consult with healthcare professionals, a long-term population approach, and organizational structure of consultation.

\section{Keywords}

Cervical Cancer Screening, Age 20 - 29, Educational Program, Information, Technology

\section{Foreword}

Over $78 \%$ of cancer cases in the AYA (adolescent and young adult) generation in Japan are female. One element of this is an increase in cases of cervical and breast cancer [1]. In a study concerning malignant tumors associated with pregnancy, of 225 cases, cervical cancer was the most common cause at $72 \%$ and $13 \%$ - 30\% chose not to continue their pregnancies [2]. Additionally, the average age of first marriage is 29.4 years and the average age at the birth of the first child is 30.7 years. This aligns with the peak age group in which cervical cancer is most often diagnosed (25 - 39). Therefore, it would be beneficial to promote regular cervical cancer screenings for women starting in their 20s [3] [4]. However, compared to other countries, which have cervical cancer screening rates of $70 \%$ $80 \%$, Japan's rate is quite low at only $43 \%$. This is even lower among women in their 20 s at only $22.2 \%$ [5] [6].

HPV vaccination is not being actively encouraged, which makes the promotion of cervical cancer screenings for women in their 20s an urgent matter in need of attention. If the screening rate is not increased, there may be an increase in cases discovered during the initial screening during pregnancy, possibly leading these women to terminate their pregnancies.

Considering the above points, it is clear that regular screenings as preventative care will help to maintain health for all women and fertility for women who intend to give birth. To this end, we implemented an educational program targeted at women in their 20s. One group of women participated in the program, while the control group did not. In this study, we compare the two groups to verify the effectiveness of the educational program.

\section{Research Method}

\subsection{Study Design}

This research is a comparative study of the intervention group, which took part 
in our educational program, and the control group, which did not.

\subsection{Subjects}

The subjects were women in their 20s who are unmarried and have not given birth and who gave permission to be included in the study. The contents of the study were specified through public advertisements, flyers, directories, and social media. The subjects decided whether to participate in a health course. The intervention group consists of those who participated in the course and the control group consists of those who did not.

\subsection{Survey Period}

April 2019-July 2020.

\subsection{Hypotheses}

1) The intervention group will score higher than the control group when tested on cervical cancer knowledge after one year.

2) The intervention group will have more positive health beliefs than the control group regarding cervical cancer screenings after one year.

3) The intervention group will show a higher rate of cervical cancer screenings than the control group after one year.

\subsection{Summary of Health Course and Education Program Leveraging IT to Distribute Information (Table 1)}

We designed an educational program aimed at preventing cervical cancer in consideration of the Health Belief Model (HBM) and past literature, referencing the health curriculum studied by high school students. The program consists of two parts: a health course followed by distributing information about cervical cancer and screenings at one and six months via images sent through IT-based methods. The contents of the course were carefully selected from Leading a Healthy Life (for high school students) [7] and Materials for Cancer Education [8] by the Ministry of Education, Culture, Sports, Science and Technology, Twelve New Provisions for Preventing Cancer [9] by the Foundation for Promotion of Cancer Research, and Cancer Prevention Based on Scientific Grounds [10] by the National Cancer Center Japan. These were discussed by a committee consisting of a doctor, a nurse, a midwife, two school nurses, and two nursing researchers (a total of 7 people). These considerations resulted in the five categories which make up the program: Toward a Healthy Lifestyle, About Cancer, About Cervical Cancer, About Cervical Cancer Screening, and the IT-based effort to promote screenings, Knowledge Review and Hospital Search Guide.

The focus of health education in Japan is preventing lifestyle-related diseases and promoting healthy, balanced lifestyle habits via the health curriculum in elementary, junior high, and high schools. First, we reviewed topics that are covered in high school, such as healthy life habits (diet, smoking, alcohol), viruses and infectious diseases, pregnancy and childbirth, and cancer prevention. 
Table 1. Content of education program.

\section{Health course}

By gaining correct knowledge of cervical cancer through the health course, subjects will understand the importance of being screened, leading to improved rates. It will also help subjects find a way to fit cervical cancer screening into their lifestyle.

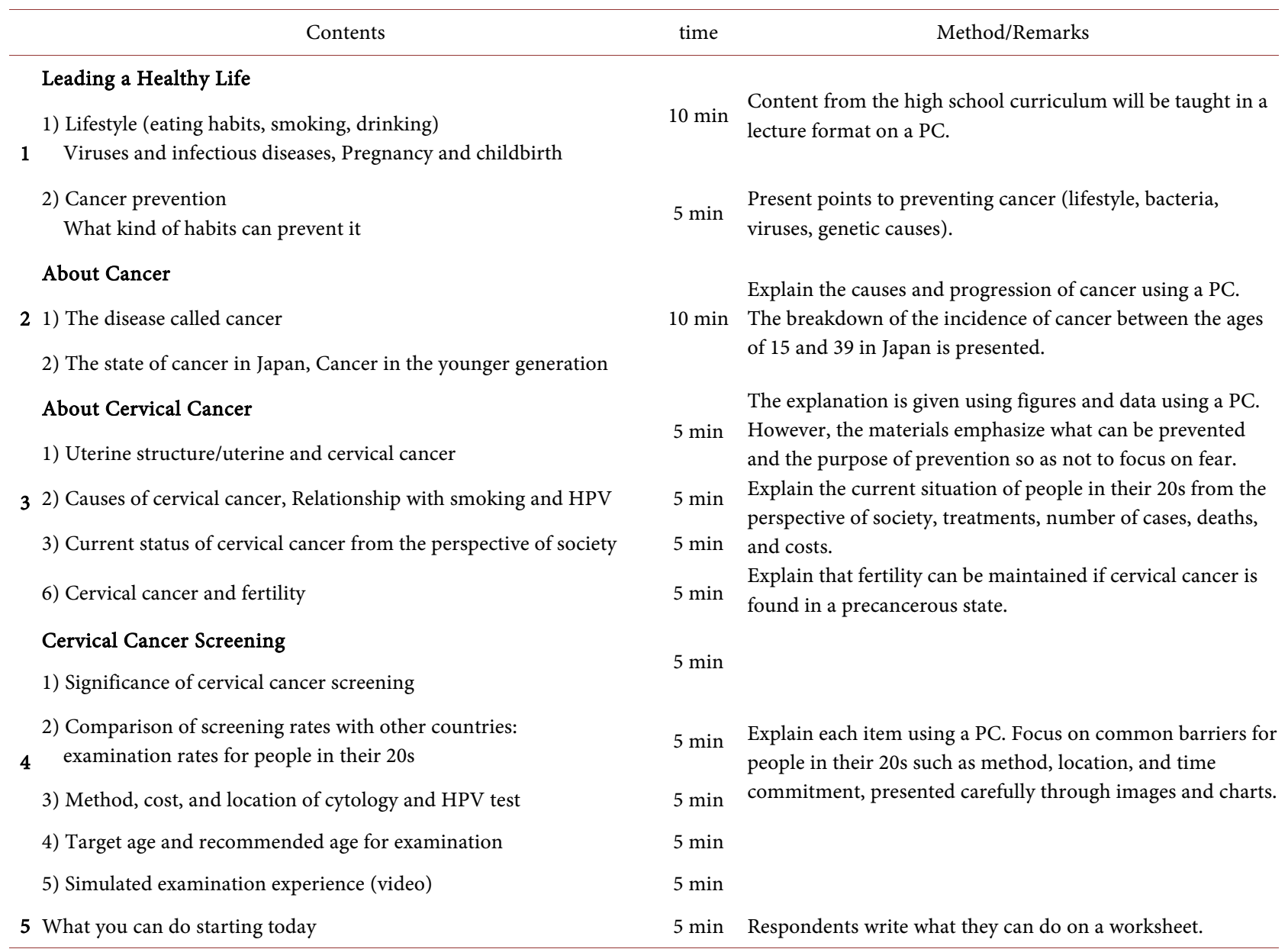

IT-based information distribution

By providing information about cervical cancer in a single image and sending information on specific costs, locations, and examination methods, it is possible to encourage subjects to seek cervical cancer screening.

\section{Contents}

Present using figures and tables to reaffirm the progression and treatment of cancer/cervical cancer. Show images of how to receive cervical cancer screening and whether or not to make an appointment, and also present information on local government and a hospital search.

We then covered cancer itself, the state of cancer in Japan, and cancer in the adolescent and young adult generation, followed by the structure of the womb, uterine and cervical cancer, causes of cervical cancer/the relationship between cervical cancer and smoking/HPV, and what can be done to maintain fertility if diagnosed with the precancerous conditions which lead to cervical cancer. We also explained the current state of cancer among women in their 20s, treatments, number of cases, deaths, and cost. To avoid giving the subjects an inflated fear of cancer, we emphasized cancer prevention and the goals of doing so. Regarding cervical cancer screenings, we presented subjects with images and figures show- 
ing the significance of cervical cancer screening, a comparison with screening rates in other countries, the screening rate of women in their 20 s, a concrete example of the screening test, and target/recommended ages for screening. Then, a video of a simulated screening was shown to allow the subjects to build a mental image of the procedure. The goal of the program was to leave this impression and lead the subjects to realize that they could take action, then and offer encouragement and support for them to seek screening in a way that fits their lifestyle. The total length of the course was approximately 75 minutes.

The health course for the intervention group was conducted with small groups a total of 44 times across the Kinki, Chugoku, Tokai, Hokuriku, and Kyushu regions of Japan, with an average size of 3.1 people.

\subsection{Data Collection Method}

\section{1) Survey Procedure and Measurement Instruments}

As part of the education program, we examined the effectiveness of the health course and the information sent via IT-based methods by having the subjects take surveys about cervical cancer screenings six months and one year later. In the surveys, the subjects responded to questions on the Health Belief Model Scale and we verified whether they had undergone a screening in that time. Based on the Stages of Behavior Change in the Transtheoretical Model (TTM), we performed interventions at one month and six months after the initial survey: one during Preparation stage, in which the subject plans to change their behavior within a month, and the other during the transition between the Action stage and Maintenance phase.

For the intervention group, the measurement periods were before, after, six months after, and one year after the health course. For the control group, they were during, six months after, and one year after the initial survey. The survey procedure is shown in Figure 1.

At the time of the initial survey, we confirmed factors which are known to be related to cervical cancer screening behavior for both groups. These factors include age, whether they have had a health exam, and past experience with gynecological care. We evaluated the effectiveness of the program based on subjects' knowledge of cancer prevention/cervical cancer screening, the Health Belief Model Scale for Cervical Cancer and Pap Smear Test (henceforth abbreviated as HBMSCCPST), and whether the subject went for a pap smear test. The knowledge tested is concerned with healthy lifestyles and cervical cancer screening, and the questions were created from items widely used in previous literature.

The HBMSCCPST is method of evaluating women's health beliefs with regard to cervical cancer screening and consists of 35 items and five factors: Pap Smear Benefits, Pap Smear Barriers, Seriousness, Susceptibility, and Health Motivation. It measures agreement with each item on a 5-point Likert scale ranging from "Strongly disagree" to "Strongly agree", with a higher score indicating a stronger degree of agreement. Gulten Guvenc has reported that this tool was found to be 


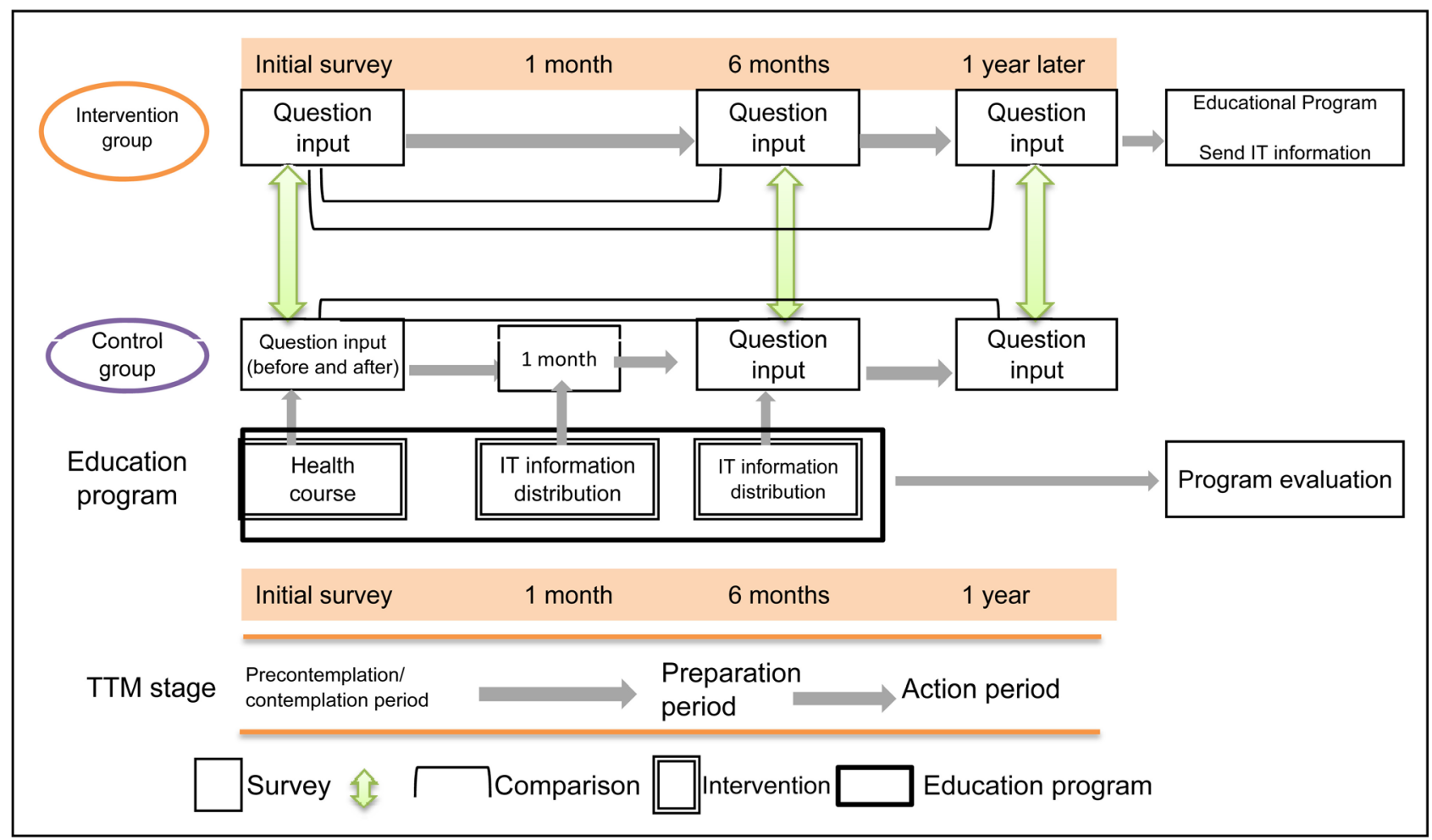

Figure 1. Survey procedure for this study.

a valid and reliable tool in assessing women's health beliefs [11] [12]. The creators and translators of the scale have acknowledged its use in this research. Construct validity has been verified through factor analysis, giving Cronbach alpha coefficients greater than 0.7. However, while the subscales of Benefits, Barriers, Seriousness, and Susceptibility had Cronbach's alpha reliability coefficients of $0.71-0.86$, the Health Motivation subscale only had a coefficient of 0.46 . Due to this, it was excluded from analysis.

\section{2) Method of Data Collection}

At the time of the initial survey, we had subjects scan a QR code containing a URL and respond to an Internet-based questionnaire. We also asked subjects in the intervention group to do so by the same method again following the health course. At six months and one year later we sent a URL to the email address register during the initial survey, which subjects were free to respond to. As a longitudinal survey, we tracked the data using a 4-digit PIN entered by each subject so the data would not contain personally identifying information. Data was entered using the online questionnaire service SurveyMonkey, which conforms to European Union General Data Protection Regulations (GDPR).

\subsection{Method of Analysis}

Survey items were analyzed according to descriptive statistics. After tallying the cervical cancer knowledge and HBMSCCPST scores using simple tabulation, the data was analyzed between the intervention and control groups. Comparison of 
the groups' attributes and knowledge/HBMSCCPST scores was done via the Mann-Whitney U Test, and repeated two-way analysis of variance was performed before, after, six months after, and one year after intervention. Before/after comparison between groups was done via the Friedman test. The number of subjects who had a pap smear test was compared via Fisher's exact test. Freeform responses were analyzed with the text mining software $\mathrm{KH}$ Coder [13]. The terms used in co-occurrence analysis were those with a Jaccard index greater than or equal to $0.2 \mathrm{KH}$ Coder is an open source software tool for computer assisted qualitative data analysis, particularly quantitative content analysis and text mining. A co-occurrence network was created by $\mathrm{KH}$ Coder based on the frequency and pattern of the extracted words. Each color indicates a cluster of words (a topic) used close together in sentences. Strongly related words are connected by lines.

\subsection{Ethical Considerations}

This research was conducted with the approval of the Osaka Medical College Research Ethics Committee. We provided a description of the research in writing (as well as verbally for the intervention group). This description explained the intentions, goals, and methods of the research, that it was voluntary, that participants could withdraw at any time, the protection of private information, and the handling of collected data. Participants were able to participate after agreeing to the terms.

\section{Results}

\subsection{Subject Attributes (Figure 2, Table 2, Table 3)}

We received responses from 145 respondents in the control group and 148 in the intervention group, for a total of 293 subjects. Our analysis excluded subjects who did not meet the requirements for this research. Valid responses were as follows (seen in Figure 2): Initial Survey: intervention group 142 (95.9\%), control group 145 (100\%); Six-Month Survey: intervention group 37 (26.1\%), control group 30 (20.7\%); One-Year Survey: intervention group 33 (23.2\%), control group 27 (18.6\%). The characteristics of the subjects are shown in Table 2. The average age of the subjects was $24.4 \pm 2.96$ years for the intervention group and $23.4 \pm 2.24$ years for the control group. No significant difference in background was observed in either group. No significant difference was seen between groups in regard to interest in cervical cancer screenings; Contemplation was the most populated stage, followed by Action, Precontemplation, and Preparation.

\subsection{Program Evaluation Regarding Initial, Six-Month, and One-Year Surveys (Table 4, Table 5)}

1) Intra-group comparison of HBMSCCPST subscales and knowledge scores

The intervention group showed a significant difference in the Benefit subscale 
Table 2. Subject characteristics.

\begin{tabular}{|c|c|c|c|c|c|c|}
\hline \multirow{3}{*}{ Age } & \multirow{3}{*}{ Average age } & \multicolumn{2}{|c|}{ Intervention $(\mathrm{n}=33)$} & \multicolumn{2}{|c|}{ Control $(\mathrm{n}=27)$} & \multirow{3}{*}{$\frac{\mathrm{p} \text {-value }}{0.148}$} \\
\hline & & & 24.4 years \pm 2.96 & & 23.4 years \pm 2.24 & \\
\hline & & \# of people & $\%$ & \# of people & $\%$ & \\
\hline \multirow{4}{*}{ Profession } & Regular employee & 18 & 54.5 & 14 & 51.9 & \multirow{4}{*}{0.862} \\
\hline & Non-regular employee & 4 & 12.1 & 3 & 11.1 & \\
\hline & Student & 10 & 30.3 & 10 & 37.0 & \\
\hline & Other & 1 & 3.0 & 0 & 0.0 & \\
\hline \multirow[b]{2}{*}{ HPV vaccination } & Yes & 13 & 39.4 & 11 & 40.7 & \multirow[b]{2}{*}{0.916} \\
\hline & No & 29 & 60.6 & 16 & 59.3 & \\
\hline \multirow{2}{*}{$\begin{array}{l}\text { Difference between residence card } \\
\text { and residential area }\end{array}$} & Same & 27 & 81.8 & 23 & 85.2 & \multirow{2}{*}{0.730} \\
\hline & Different & 6 & 18.2 & 4 & 14.8 & \\
\hline \multirow{2}{*}{ Previously seen by gynecologist? } & Yes & 18 & 54.5 & 10 & 37.0 & \multirow{2}{*}{0.180} \\
\hline & No & 15 & 45.5 & 17 & 63.0 & \\
\hline \multirow{2}{*}{$\begin{array}{l}\text { Previously had cervical cancer } \\
\text { screening? }\end{array}$} & Yes & 9 & 27.3 & 10 & 37.0 & \multirow{2}{*}{0.422} \\
\hline & No & 24 & 72.7 & 17 & 63.0 & \\
\hline \multirow{2}{*}{ Smoker? } & Yes & 1 & 3.0 & 2 & 7.4 & \multirow{2}{*}{0.443} \\
\hline & No & 32 & 97.0 & 25 & 92.6 & \\
\hline
\end{tabular}

Mann-Whitney U test.

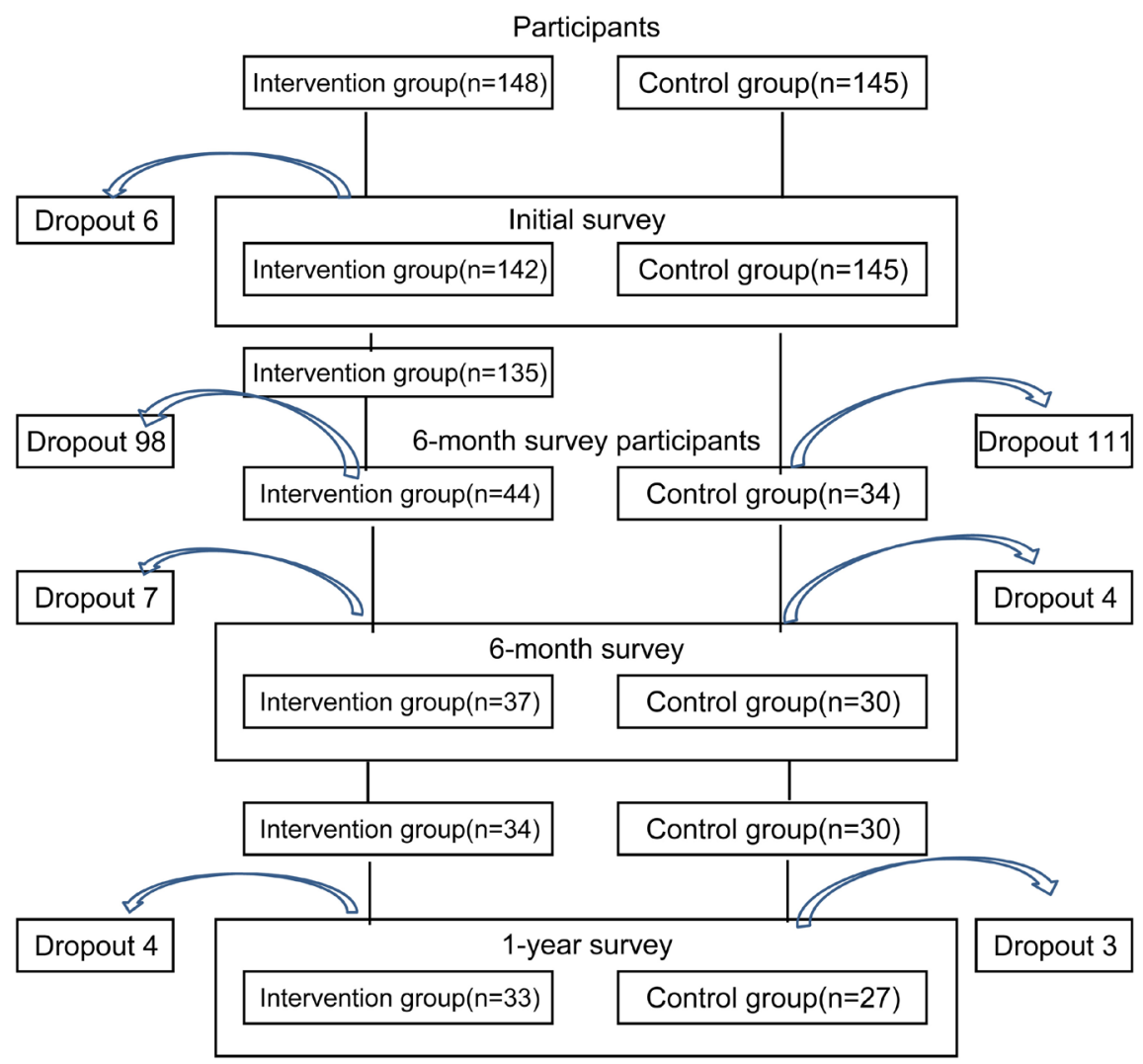

Figure 2. Flow diagram. 
Table 3. Participant interest in screening.

\begin{tabular}{|c|c|c|c|c|c|}
\hline \multirow{2}{*}{ Stage of Interest } & \multicolumn{2}{|c|}{ Intervention group $(\mathrm{n}=33)$} & \multicolumn{2}{|c|}{ Control group $(\mathrm{n}=27)$} & \multirow{2}{*}{ p-value } \\
\hline & \# of people & $\%$ & \# of people & $\%$ & \\
\hline $\begin{array}{l}\text { Precontemplation } \\
\text { Never had a Pap test and not thinking about having one in the next } 6 \text { months }\end{array}$ & 4 & 12.1 & 7 & 25.9 & \\
\hline $\begin{array}{l}\text { Contemplation } \\
\text { Never had a Pap test but thinking about having one in the next } 6 \text { months }\end{array}$ & 19 & 57.6 & 13 & 48.1 & 0355 \\
\hline $\begin{array}{l}\text { Preparation } \\
\text { Never had a Pap test but thinking about having one in the next month }\end{array}$ & 1 & 3.0 & 0 & 0.0 & 0.035 \\
\hline $\begin{array}{l}\text { Action } \\
\text { Had a Pap test in the past and intend to again }\end{array}$ & 9 & 27.3 & 7 & 25.9 & \\
\hline
\end{tabular}

Mann-Whitney U test.

Table 4. Comparison of knowledge and HBMSCCPST scores in the initial 6-month and 1-year survey.

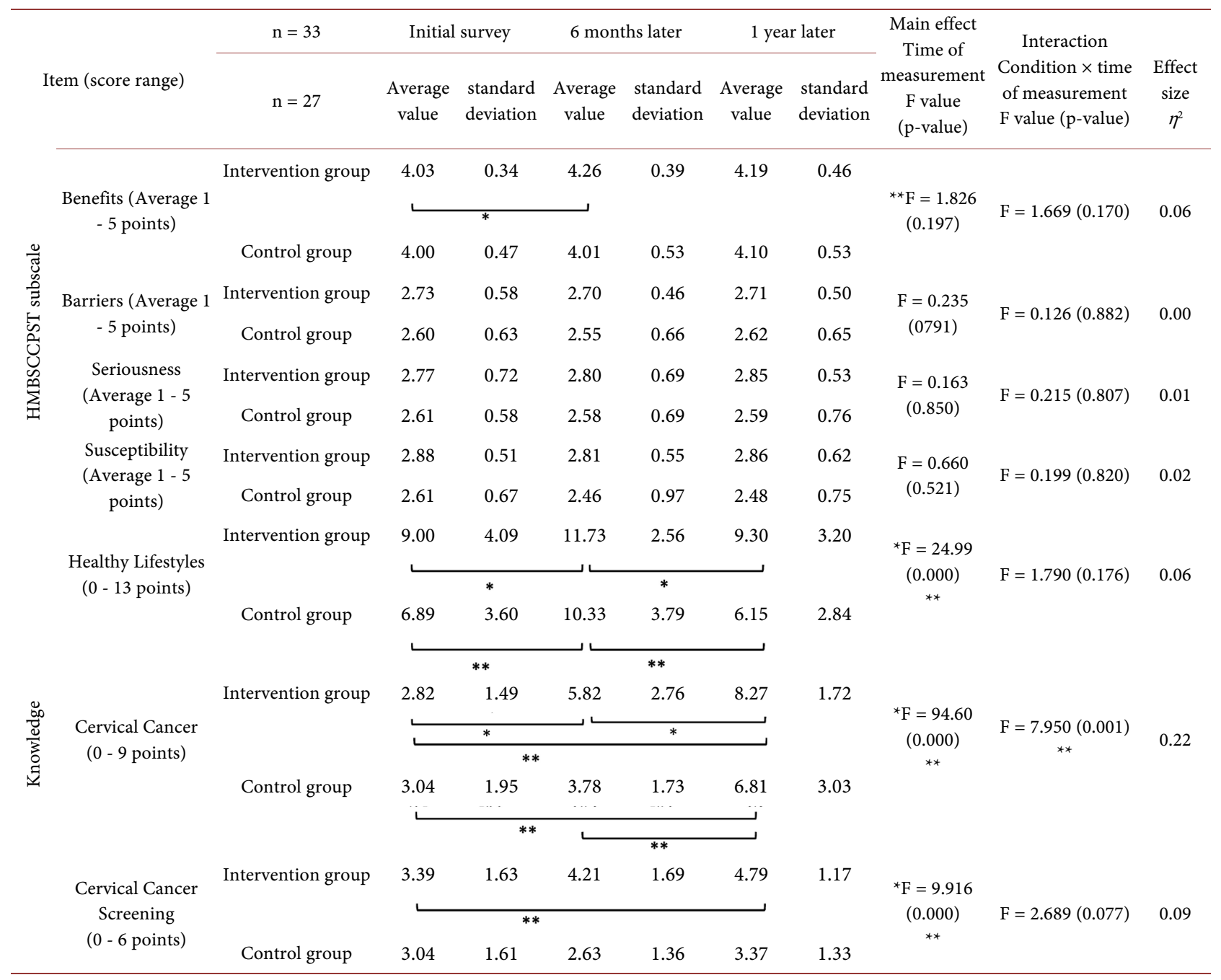

Two-way ANOVA. ${ }^{* *} \mathrm{p}<0.01 ;{ }^{*} \mathrm{p}<0.05$.

of the HBMSCCPST in the six-month survey $(\mathrm{p}=0.017)$. Scores in the Healthy Lifestyles knowledge category were significantly higher than the initial survey $(p=$ 
Table 5. Inter-group comparison of changes in knowledge and HBMSCCPST scores between initial and 1-year surveys.

\begin{tabular}{|c|c|c|c|c|c|c|c|}
\hline & \multirow[b]{2}{*}{ Item } & \multicolumn{2}{|c|}{ Intervention group $(\mathrm{n}=33)$} & \multicolumn{2}{|c|}{ Control group $(n=27)$} & \multirow[b]{2}{*}{ p-value } & \multirow{2}{*}{$\begin{array}{l}\text { Effect } \\
\text { size } \gamma\end{array}$} \\
\hline & & $\begin{array}{l}\text { Average } \\
\text { value }\end{array}$ & $\begin{array}{l}\text { Standard } \\
\text { deviation }\end{array}$ & $\begin{array}{l}\text { Average } \\
\text { value }\end{array}$ & $\begin{array}{l}\text { Standard } \\
\text { deviation }\end{array}$ & & \\
\hline \multirow{4}{*}{ 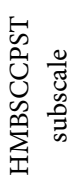 } & Benefits & 0.155 & 0.509 & 0.093 & 0.562 & 0.612 & -0.07 \\
\hline & Barriers & -0.195 & 0.611 & 0.019 & 0.652 & 0.592 & 0.07 \\
\hline & Seriousness & 0.078 & 0.469 & -0.027 & 0.757 & 0.788 & -0.10 \\
\hline & Susceptibility & -0.020 & 0.601 & -0.136 & 0.807 & 0.424 & -0.04 \\
\hline \multirow{3}{*}{ 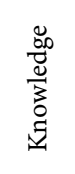 } & Healthy Lifestyle & 0.300 & 4.559 & -0.740 & 4.221 & 0.267 & -0.14 \\
\hline & Cervical Cancer & 5.450 & 2.399 & 3.780 & 2.913 & $0.027^{\star}$ & -0.29 \\
\hline & $\begin{array}{c}\text { Cervical Cancer } \\
\text { Screening }\end{array}$ & 1.390 & 2.061 & 0.330 & 1.617 & $0.016^{*}$ & -0.31 \\
\hline
\end{tabular}

Mann-Whitney U test. ${ }^{*} \mathrm{p}<0.05$.

0.003) or the one-year survey $(\mathrm{p}=0.001)$. In the Cervical Cancer category scores were significantly higher after one year than in the initial survey $(\mathrm{p}=0.000)$ or after six months $(\mathrm{p}=0.000)$. In the Cervical Cancer Screening category scores had increased significantly after one year compared to the initial survey $(p=0.001)$.

The control group showed no significant differences in the HBMSCCPST subscales. In the Healthy Lifestyles knowledge category scores were significantly higher after six months than in the initial survey $(\mathrm{p}=0.005)$ or after one year $(\mathrm{p}$ $=0.004)$. In the Cervical Cancer category scores were significantly higher after one year than in the initial survey $(\mathrm{p}=0.000)$ or after six months $(\mathrm{p}=0.043)$.

2) Inter-group comparison of HBMSCCPST subscales and knowledge scores

After comparing the one-year surveys of both groups, significant differences were shown in the Healthy Lifestyles $(p=0.000)$ and Cervical Cancer Screening $(p=0.000)$ categories. We observed significant differences in score changes between the initial survey and one-year survey in the Cervical Cancer $(p=0.027)$ and Cervical Cancer Screening $(\mathrm{p}=0.016)$ categories. A small effect size was observed on Healthy Lifestyles $(\gamma=-0.14)$ and Seriousness $(\gamma=-0.10)$.

Changes in HBMSCCPST subscales and knowledge scores were examined via two-way analysis of variance of condition (intervention/control group) and time of measurement (initial survey, six months, one year). A significant main effect and interaction were observed in the intervention group in the Cervical Cancer category $\left[\mathrm{F}(2,57)=7.95, \mathrm{p}=0.00, \eta^{2}=0.22\right]$ with a large effect size. A main effect and medium effect size was observed in the knowledge categories Healthy Lifestyles $\left[\mathrm{F}=1.669, \mathrm{p}=0.17, \eta^{2}=0.06\right]$ and Cervical Cancer Screening $[\mathrm{F}(2,57)$ $\left.=18.012, p=0.00, \eta^{2}=0.09\right]$. On the other hand, no interaction was observed in the HBMSCCPST subscales. However, a medium effect size was seen in the Benefits subscale $\left[\eta^{2}=0.06\right]$, and small effect sizes in the Seriousness $\left[\eta^{2}=0.01\right]$ and Susceptibility $\left[\eta^{2}=0.02\right]$ subscales. No effect size was shown in the Barriers subscale.

3) Program Evaluation (Figure 3)

After one year we requested thoughts and opinions on the program. 33 subjects provided input. A total of 765 words consisting of nouns, verbs, adjectives, 


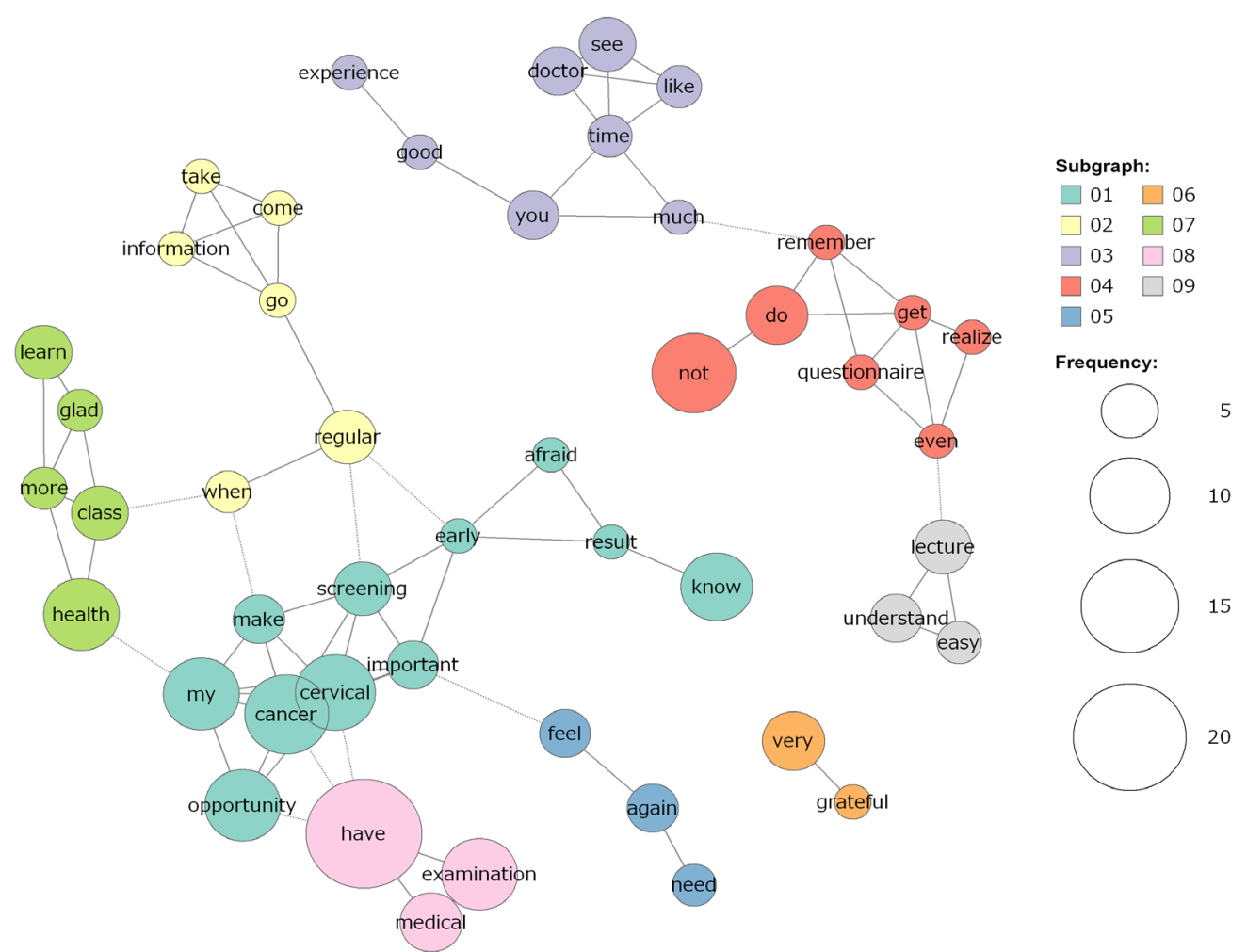

Figure 3. Co-occurrence network of opinions and impressions of educational program.

and adverbs were extracted for analysis. The average frequency of each word was 2.2, with a standard deviation of 3.0. As a result of a co-occurrence network analysis which searches the extracted words for shared links and similar patterns, 9 subgraphs were extracted as shown in Figure 3: Cervical Cancer Screening Opportunities, Health Course Teachings, Reaffirming Importance, Screening Consultation, Understandable Lecture, Regular Information, Realizations from Survey, Time and Experience for Screening, and Positive Impressions. We found the words shikyukeigan (cervical cancer), kenshin (health screening), jushin (medical exam/consultation), and kikai (opportunity) mediated with a large number of words. Health Course Teachings was connected to Cervical Cancer Opportunities. Reaffirming Importance and Regular Information were connected to Screening Consultation. Respondents realized the importance of their own health from Understandable Lecture and Realizations from Survey, connecting to Time and Experience for Survey. Health Course Teachings and Understandable Lectures were not connected, however.

\subsection{Cervical Cancer Screening Consulting Behavior (Table 6)}

While no significant difference was found in the percentage of subjects who had had a cervical cancer screening after one year, a small-degree effect size was observed. Of the intervention group, 10 (30.3\%) had a screening versus 4 (14.8\%) in the control group. In both groups, the most common reason for being tested was "Recommended by healthcare provider". For the intervention group the 
Table 6. Relationship between cervical cancer screening and HMBSCCCPST subscale/knowledge score.

\begin{tabular}{|c|c|c|c|c|c|c|c|}
\hline & \multirow[b]{2}{*}{ Item } & \multicolumn{2}{|c|}{ Intervention group $(\mathrm{n}=14)$} & \multicolumn{2}{|c|}{ Control group $(n=46)$} & \multirow[b]{2}{*}{$\mathrm{p}$-value } & \multirow[b]{2}{*}{ Effect size $\gamma$} \\
\hline & & $\begin{array}{l}\text { Average } \\
\text { value }\end{array}$ & $\begin{array}{l}\text { Standard } \\
\text { deviation }\end{array}$ & $\begin{array}{l}\text { Average } \\
\text { value }\end{array}$ & $\begin{array}{l}\text { Standard } \\
\text { deviation }\end{array}$ & & \\
\hline \multirow{4}{*}{ 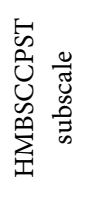 } & Benefits & 4.23 & 0.41 & 4.12 & 0.50 & 0.212 & -0.10 \\
\hline & Barriers & 2.46 & 0.27 & 2.73 & 0.58 & 0.659 & 0.25 \\
\hline & Seriousness & 2.76 & 0.27 & 2.72 & 0.72 & 0.560 & -0.03 \\
\hline & Susceptibility & 2.90 & 0.26 & 2.62 & 0.76 & 0.435 & -0.17 \\
\hline \multirow{3}{*}{ 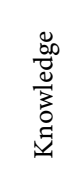 } & Healthy Lifestyle & 8.93 & 0.26 & 7.57 & 3.59 & 0.052 & -0.16 \\
\hline & Cervical Cancer & 7.71 & 0.14 & 7.59 & 1.43 & 0.813 & -0.08 \\
\hline & $\begin{array}{l}\text { Cervical Cancer } \\
\text { Screening }\end{array}$ & 4.29 & 0.26 & 4.11 & 2.49 & 0.192 & -0.06 \\
\hline
\end{tabular}

Mann-Whitney U test. ${ }^{*} \mathrm{p}<0.05$.

next most common reasons were "Health course" and "Recommended by workplace". For the control group, the next most common reasons given were "Free voucher" and "Recommended by mother". Reasons given for not being tested were, in order of frequency for both groups, "Didn't have the chance", "Didn't have time", "don't know how to get one", and "because of the COVID-19 pandemic". $64.3 \%$ of screenings were done at the discretion of the patient, with the rest being done through workplace health examinations, etc. Of those, $42.9 \%$ each were funded personally or through municipal financial aid. There were no significant differences associated with knowledge scores or HBMSCCPST subscales and the whether subject had a cervical cancer screening or not. However, a small-degree effect size was found in Benefits $(\gamma=-0.10)$, Barriers $(\gamma=-0.25)$, Susceptibility $(\gamma=-0.17)$, and Healthy Lifestyles $(\gamma=$ $-0.16)$. Additionally, there was no significant difference in interest in the level of cervical cancer screening or consulting behavior.

\section{Considerations}

\subsection{Subject Characteristics}

In this study, we examined the intervention effect of an education program on women in their 20s aimed at promoting cervical cancer screenings. There were no significant differences in the backgrounds of the intervention and control groups. We predicted there would be differences in the TTM stages of interest regarding cervical cancer screening between the intervention and control groups, however no differences were found in either group. According to the RE-AIM (Reach, Efficacy, Adoption, Implementation, and Maintenance) framework proposed by Glasgow, external validity was captured with regards to preventive interventions on health [14].

\subsection{Effectiveness of Education Program}

Studies both in and outside Japan regarding the prevention of cervical cancer 
have made it clear that education programs have a positive effect on knowledge [15] [16]. In our study as well, we observed main effects and interactions in knowledge categories from the initial survey and six-month and one-year surveys and a small effect size, we consider this the health program to have had an effect on knowledge scores. Additionally, while significant differences were not shown in HBMSCCPST subscales, small-degree effect sizes were shown in Benefit, Seriousness, and Susceptibility. Haywood has proposed individual counselling, goal setting, and group counselling as methods of intervention [17]. Because this study was carried out in small groups with the steps of a cervical cancer screening shown visually through video, we believe that not only did subjects' knowledge improve, but that they were able to build a mental image of the procedure. On the other hand, the control group showed a significant difference in knowledge scores in Healthy Lifestyles and Cervical Cancer. We presumed that these differences occurred due to the Healthy Lifestyles category being based on the high school curriculum; subjects were reminded of what they had learned in the past. We also inferred that being involved with the survey itself may have served as an impetus for subjects to learn more about cervical cancer on their own.

In past studies, increasing knowledge of diseases and their prevention was shown to be related to improvement in the Susceptibility and Seriousness HBMSCCPST subscales as well as the Benefits and Barriers to preventive behavior [18]. While our study showed an increase in knowledge scores, we did not see an improvement in the Seriousness HBMSCCPST subscale. Objective information alone is not enough to move people to change; impressions are important. For a web-based health counselling program, creative and innovative methods of intervention are necessary to increase and maintain subjects' interest amid a digital environment flooded with information [19] [20]. That is, the images from the health course and the IT-based screening promotion designed for the Digital Native generation did not increase interest or lead to health consulting behavior for women in their 20s. A population-based approach must be considered that is more helpful to women in this age group while still being offered in a timely manner.

\subsection{Cervical Cancer Screening Consultation Behavior}

No significant difference was observed in the number of subjects having cervical screenings done as a result of the intervention. The rate of subjects in the control group which had a screening was the same as the average for all women in their 20 s in Japan (22.2\%), while the intervention group was above average at $30.3 \%$. For screening behavior, whether the subject takes action or not depends on if they are more conscious of the benefits or the barriers or preventative action. The promotion of cervical cancer screening will require not only information distribution, but also a reduction in perceived barriers [21] [22]. While our study showed an improvement in Benefits, Seriousness, and Susceptibility, the lack of change in Barriers suggests it did not lead to screening behavior. In their re- 
search, P.H. Youl et al. sent out continuous text messages about preventing disease and implemented a follow-up program after three months. Afterward, they continued to promote preventative behavior by sending monthly text messages [23]. In our research, text messages were sent after the first month and sixth month. This had an effect on Benefits after six months, but it did not continue to one year. In addition, in the free description of the educational program, the effect of the lecture and words indicating the importance of cervical cancer were generally positive, but the images sent using IT were not mentioned. This suggests that a more long-term follow-up is necessary to make subjects understand the value of cervical cancer screening and stimulate the screening rate among women in their 20s.

Reasons given for being tested include recommendations from the healthcare provider or mother and having a free voucher. The majority of screenings were done at the patients' discretion. Reasons given in both groups for not being tested were a lack of time or opportunity.

In Japan, because financial aid for cervical cancer screenings differs based on municipality, free vouchers are only valid where patients have a certificate of residence. Additionally, for screenings covered through the workplace, the method of applying for compensation varies. The most common routes for screening are through the municipality for college students and through the workplace for the general population, so these entities also serve an important role regarding surveys [24] [25].

A survey in Sweden has reported a method of promoting cervical cancer screenings. When patients come in for their first screening, a special appointment is made to provide adequate time and support. The time and place of the screening, as well as which specialist the patient will see is set in advance. It can also be combined with other tests, promoting future visits. Furthermore, in the school health curriculum school nurses serve a special function that produces great results [26]. That is, strategies for the first screening and the organizational structure of consultations must be considered. As it will influence life events in their 20s such as pregnancy and childbirth, it is important to continuously educate young women on reproductive health through the school curriculum according to the stages of development and build awareness of the free vouchers at an early stage.

\subsection{Results of Hypothesis Testing}

1) The intervention group will score higher than the control group when tested on cervical cancer knowledge after one year: Partially validated due to significant increase in Healthy Lifestyles, Cervical Cancer Screening, and Cervical Cancer scores.

2) The intervention group will have more positive health beliefs than the control group regarding cervical cancer screenings after one year: Not validated, but a small-degree effect size was observed in Benefits, Seriousness, and Susceptibil- 
ity scores.

3) The intervention group will show a higher rate of cervical cancer screenings than the control group after one year: Not validated. The screening rate of the control group was the same as the average among women in their 20s in Japan. However, the intervention group showed a rate of $30.3 \%$, which was above the average.

\section{Limits of Research and Future Tasks}

The limits of this research were the small sample size and the fact that the selection of subjects did not include women from every part of Japan. It is necessary to verify with a larger number of subjects. Additionally, low socioeconomic attributes correlate to lower standards of health behavior and there is a tendency to see more success among more highly educated and higher income groups [27] [28]. Furthermore, in Japan the screening environment differs based on municipality. There is a need for the development of an education program which takes into account the background and education of the subjects as well as their environment.

\section{Conclusions}

The subjects of health education program implemented in this study to promote cervical cancer screenings among women in their 20 s showed significantly higher knowledge and cervical cancer and healthy lifestyles in the intervention group than those of the control group. A small-scale effect size was observed in HBMSCCPST subscales and cervical cancer screening behavior. Additionally, a small-scale effect size was observed in knowledge and HBMCCPST subscales in the comparison of individuals who had a screening exam versus those who did not.

This suggests that the health education program was connected to knowledge retention after one year and was somewhat effective at influencing HBMSCCPST subscales and cervical cancer screening behavior. However, because the educational program was limited to one session and the sample size was small, it did not lead to precise results. The program must be reevaluated while considering regional characteristics, health behaviors, and economic elements in order to effectively bring about behavioral change.

\section{Acknowledgements}

We would like to thank the participants for their cooperation in making this study possible and the developers of the Health Belief Model Scale for Cervical Cancer and Pap Smear Test for graciously allowing us to reference their work. We would also like to express our gratitude for the guidance of Prof. Ayako Sasaki, Prof. Kumi Suzuki, Prof. Tomotaro Dote, and Prof. Yumiko Nakashita of the Osaka Medical College Department of Nursing Science. This study was funded with the assistance of the Health Science Center. 


\section{Conflicts of Interest}

The authors declare no conflicts of interest regarding the publication of this paper.

\section{References}

[1] Katanoda, K., Shibata, A., Matsuda, T., Hori, M., Nakata, K., Narita, Y., Ogawa, C., Munakata, W., Kawai, A. and Nishimoto, H. (2017) Childhood, Adolescent and Young Adult Cancer Incidence in Japan in 2009-2011. Japanese Journal of Clinical Oncology, 47, 762-771. https://ganjoho.jp/data/reg_stat/statistics/brochure/2016 2017 icccaya.pdf

[2] Ikeda, T., Ikenogami, K., Okamura, S., et al. (2018) Jinkōninshinchūzetsu, ninsanpushibō no chi'iki kakusa ni kansuru kenkyū [A Study on Regional Disparities in Abortion and Maternal Death.] http://admin7.aiiku.or.jp/ doc/houkoku/h24/19017A010.pdf

[3] Kokuritsu Gan Kenkyū Sentaa Gan Jōhō Saabisu. Gan Tōroku/Tōkei. [National Cancer Center Cancer Information Service. Cancer Registry \& Statistics]. https://ganjoho.jp/reg_stat/statistics/stat/summary.html

[4] Ministry of Health, Labor and Welfare (2018) White Paper on Statistical Information of Current Population Survey. https://www.mhlw.go.jp/toukei/list/81-1a.html

[5] Cancer Registry and Statistics (2018) Cancer Information Service. National Cancer Center, Japan. https://ganjoho.jp/reg_stat/statistics/stat/screening.html

[6] OECD (2014) Zuhyō de miru sekai no hoken'iryō OECD indike-ta (2013-ban). [Global Health and Medical Care as Seen in Charts: OECD Indicator (2013 Edition)]. Tokyo Akashishoten.

[7] Ministry of Education (2018) Leading a Healthy Life (for High School Students). https://www.mext.go.jp/a menu/kenko/hoken/08111805.htm

[8] Ministry of Education (2017) Teaching Materials to Advance Cancer Education. http://www.mext.go.jp/a menu/kenko/hoken/1369992.html

[9] Foundation for Promotion of Cancer Research (2018) 12 New Articles to Prevent Cancer. https://www.fpcr.or.jp/pdf/p21/12kajyou 2019 1114.pdf

[10] National Cancer Center Cancer Information Service (2018) Scientifically-Based Cancer Prevention. https://ganjoho.jp/data/public/qa links/brochure/knowledge/301.pdf

[11] Guvenc, G., Akyuz, A. and Açikel, C.H. (2010) Health Belief Model Scale for Cervical Cancer and Pap Smear Test: Psychometric Testing. Journal of Advanced Nursing, 67, 428-437. https://doi.org/10.1111/j.1365-2648.2010.05450.x

[12] Shimizu, K. and Ishida, S. (2014) Shiyukeigankainyū puroguramu no kōka no kentō [Examination of the Effect of Cervical Cancer Intervention Program]. Journal of the Japanese Society of Health Medicine, 22, 264-271.

[13] Higuchi, K. (2014) Shakaityōsa notameno keiryō tekisutobunseki [Quantitative Text Analysis for Social Research]. Nakanishiya Publishing, Kyoto.

[14] Glasgow, R.E., Bull, S.S., Gillette, C., Klesges, L.M. and Dzewaltowski, D.A. (2002) Behavior Change Intervention Research in Healthcare Settings: A Review of Recent Reports with Emphasis on External Validity. American Journal of Preventive Medicine, 23, 62-69. https://doi.org/10.1016/S0749-3797(02)00437-3

[15] Pirzadeh, A. and Mazaheri, M.A. (2012) The Effect Education on Women's Practice Based on the Health Belief Model about Pap Smear Test. International Journal of 
Preventive Medicine, 3, 585-590.

[16] Ikeda, M. and Kimura, C. (2014) Daigakusei/seijinjyosei ni taisuru sikyukeigan yobō kyōiku puroguramu no jisen to hyōka [Practice and Evaluation of Cervical Cancer Prevention Education Program for University Students and Adult Women]. Journal of Japan Society of Health Sciences, 17, 86-94.

[17] Haywood, K., Marshall, S. and Fitzpatrick, R. (2006) Patient Participation in the Consultation Process. A Structured Review of Intervention Strategies. Patient Education and Counseling, 63, 12-23. https://doi.org/10.1016/j.pec.2005.10.005

[18] Nakagawa, Y. (1991) Igakukyōiku ni okeru taikengakushyū [Experiential Learning in Medical Education]. Monthly Nursing, 11, 56-57.

[19] Alison, L.M., Eva, R.L., Adrian, E.B., et al. (2003) Print versus Website Physical Activity Programs. A Randomized Trial. American Journal of Preventive Medicine, 25, 88-94. https://doi.org/10.1016/S0749-3797(03)00111-9

[20] Yasukata, F. (2010) Tōnyōbyō kanjya no serufumanejimento kyōiku kaisei 2 han Wakaru! Tsukaeru! Yaruki wo takameru! Empauwamento to jikokōryoku. [Self-Management Education for Diabetic Patients Revised 2nd Edition-Understand! Use! Increase Motivation! Empowerment and Self-Efficacy]. Medica Publishing, Osaka.

[21] Hasegawa, F. and Kitagawa, M. (2015) Joshidaisei no shikyūkeigan kenshin ni taisuru ninshiki to kōdō no kanren [The Relationship between Awareness and Behavior of Female University Students for Cervical Cancer Screening]. Adolescent Studies, 33, 172-185.

[22] Imamura, M., Yoshida, K., Tsukada, H., et al. (2017) Kangokei jyoshidaigakusei ga jishi shita jyoshikoukousei he no shikyūkeigan yobō keihatsu katsudō no kōka [Effect of Education Delivered by Female Nursing Students to High School Girls about Preventing Cervical Cancer]. Ishikawa Journal of Nursing, 14, 59-69.

[23] Youl, P.H., Soyer, H.P., Baade, P.D., et al. (2015) Can Skin Cancer Prevention and Early Detection Be Improved via Mobile Phone Text Messaging? A Randomised, Attention Control Trial. Preventive Medicine, 71, 50-56.

https://doi.org/10.1016/j.ypmed.2014.12.009

[24] Okamura, K., Nakagoshi, R. and Norimatsu, Y. (2013) Nijyussaidaikinroujosei no shikyūkeigankenshinjushin kōdō to kanrenyōin no kentō [Examination of Cervical Cancer Screening Behavior and Related Factors of Working Women in Their 20s]. Journal of Shikoku Public Health Society, 58, 152-159.

[25] Kawai, H., Takayama, S. and Imai, M. (2010) Shikyūkeigankenshin no jyushin kōdō ni kakawaru inshi no kentō [Examination of Factors Related to Cervical Cancer Screening Consultation Behavior]. Ishikawa Nursing Magazine, 7, 59-69.

[26] Blomberg, K., Tishelman, C., Ternestedt, B.M., et al. (2011) How Can Young Women Be Encouraged to Attend Cervical Cancer Screening? Suggestions from Face-to-Face and Internet Focus Group Discussions with 30-Year-Old Women in Stockholm, Sweden. Acta Oncologica, 50, 112-120.

https://doi.org/10.3109/0284186X.2010.528790

[27] Adler, N.E. and Newman, K. (2002) Socioeconomic Disparities in Health: Pathways and Policies. Health Affairs, 21, 60-70. https://doi.org/10.1377/hlthaff.21.2.60

[28] Qi, V., Phillips, S.P. and Hopman, W.M. (2006) Determinants of a Healthy Lifestyle and Use of Preventive Screening in Canada. BMC Public Health, 6, Article No.: 275. https://doi.org/10.1186/1471-2458-6-275 